Review

\title{
Demographic transition and potential for development: the case of Iraqi Kurdistan
}

\author{
T.S. Al-Hadithi, ${ }^{1}$ N.P. Shabila, ${ }^{1}$ N.G. Al-Tawil' and S.M. Othman ${ }^{1}$
}

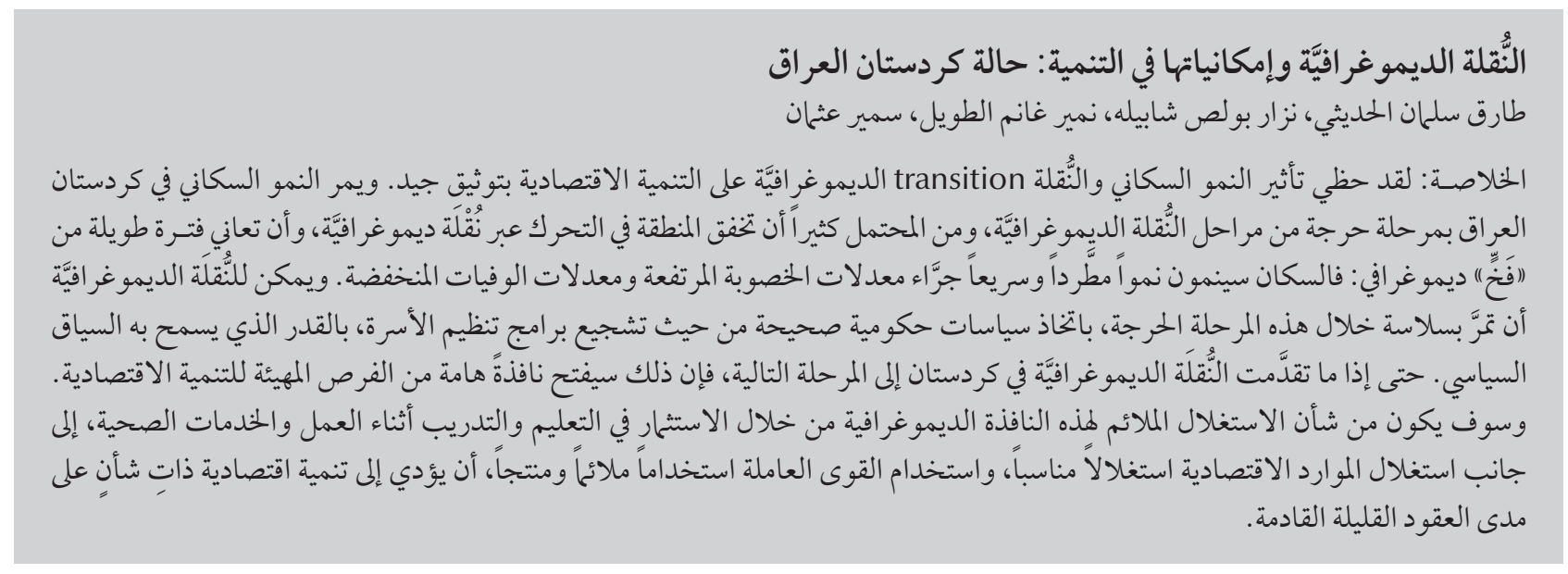

ABSTRACT The effect of population growth and demographic transition on economic development has been well documented. The population growth in Iraqi Kurdistan is passing through a critical stage of demographic transition. It is, in fact, extremely likely that the region will fail to efficiently move through the demographic transition and will experience a long period in the demographic trap, i.e. the population will grow steadily and rapidly owing to the high fertility and low mortality rates. With correct government policies in terms of promoting family planning programmes, should the political context allow, demographic transition can pass smoothly through this critical stage. Furthermore, if demographic transition in Kurdistan moves to the next stage, it will provide an important window of opportunity for economic development. Proper exploitation of this demographic window through investment in education, on-the-job training and health services, in addition to proper and appropriate exploitation of economic resources and suitable and productive use of the labour force, will result in significant economic development over the next few decades.

\section{Transition démographique et potentiel de développement : le cas du Kurdistan irakien}

RÉSUMÉ L'effet de la croissance et de la transition démographiques sur le développement économique a été prouvé. La croissance démographique au Kurdistan irakien est entrée dans une phase cruciale. En réalité, il est fort probable que la région ne traversera pas aisément la transition démographique et connaitra une longue période de "piège démographique » : la population augmentera régulièrement et rapidement en raison d'un taux de fécondité élevé et d'un faible taux de mortalité. Avec une politique gouvernementale appropriée promouvant des programmes de planification familiale - si le contexte politique le permet, la transition démographique pourrait traverser sans heurts cette phase cruciale. En outre, si celle-ci passe au stade suivant, elle constituera une période très propice au développement économique. La mise à profit de cette opportunité démographique par l'investissement dans l'éducation, la formation en cours d'emploi et les services de santé entraînera un développement économique important dans les prochaines décennies, si elle est associée à une exploitation appropriée des ressources économiques et à une utilisation adaptée et productive de la population active. 


\section{Introduction}

The implication of population growth on economic development has been an issue of long-standing debate [1]. A number of studies have tackled this issue, leading to the emergence of many views and theories that have varied enormously over time. Generally speaking, there have been 3 positions regarding such implications: one optimistic, one neutral and the other pessimistic $[2,3]$. The pessimists considered rapid population growth an obstacle to economic development and a trap for the poor countries where all efforts will go to addressing the needs of the larger population while maintaining them under poorer and deteriorating conditions. The proponents of the neutral position denied any significant implications of population growth and attributed poverty to other factors such as government policies and institutional defects. The optimists went even further to emphasise the importance of population growth as a stimulant for technological progress and economic development [1].

Population growth came onto the agenda only around the 18th century. Prior to this, the high fertility required mainly for supporting agricultural activities was counterbalanced by the high mortality. The high mortality was due to the effects of low level of health and socioeconomic conditions, including famines, unsanitary living conditions, disease, and general poverty [4]. The high population growth rates noticed in the 20th century were a result of the substantial decline in mortality and the continued high and sustained fertility, in particular in the developing countries [5].

The current total fertility rate is around 1.4 in Europe, 2.4 in Asia and Latin America and 5.0 in Sub-Saharan Africa [6]. Even though the total fertility rate in Iraq significantly decreased from 7.2 in 1970 to 5.9 in 1990 and to 4.07 in 2007 , the rate is still very high [7]. The
Iraqi Kurdistan region had the same total fertility rate (4.07) in 2007; this is projected to be 3.32 in 2015 , which is still high $[7,8]$.

In 2005 the global population was around 6.6 billion and is projected to be 9 billion in 2050; ranging from 7.7 to 10.6 billion depending on future fertility [7]. Currently rapid population growth at rates above $2 \%$ is common in most developing countries, especially in Africa [5]. In Iraq, the annual population growth rate of $3 \%$ in the $1990 \mathrm{~s}$ has decreased to $2.62 \%$ in 2007 , which is still in the rapid growth category. This is projected to continue at a high level even in 2015, with an estimated rate of $2.18 \%$ [7]. The present annual population growth in Iraqi Kurdistan is estimated at $2.75 \%$, and a high rate is projected to continue till $2015[7,8]$.

This review discusses the different views and theories on the implications of rapid population growth on economic development. It also attempts to examine the experience of a number of regions of the world regarding the impact of population growth on economic development. More specifically, it puts greater emphasis on the situation in Iraqi Kurdistan and tries to give an understanding of the trend in this region through analysing the existing data and information and comparing it with the experience of other regions.

The specific population characteristics or figures for Iraqi Kurdistan, wherever available, have been used throughout this review, whereas the population estimates and projections for Iraq as a whole have been used in cases where specific data for Iraqi Kurdistan were unavailable.

\section{Review}

\section{Population debate}

Thomas Malthus, in his famous "First Essay on Population" in 1798, argued that population would grow more quickly than food production and went on to strongly suggest that rapid population growth hinders economic development $[2,9]$. The experience of the next 2 centuries revealed that Malthus' predictions were not sustained as people consciously managed fertility due to changing conditions. Furthermore, food production expanded as a result of advances in technology [1].

Another famous contribution to the population debate came from Ester Boserup, who argued that population growth increases settlement densities and creates pressure on resources and thus stimulates innovation and improvement in agricultural technology [10].

Recent studies put more emphasis on the impact on economic development of factors other than population growth alone. These studies stressed the importance of factors like family planning, age structure, and government policies and investment in determining economic development [2].

\section{Demographic transition}

Demographic transition is a 4-stage model that describes population change when a country moves from high to low fertility and mortality rates as part of economic development [11].

Stage 1 is associated with predevelopment time and is characterised by high but approximately balanced fertility and mortality rates. Consequently, this stage results only in very slow population growth [10].

In stage 2 , the mortality rate declines as a result of significant improvements in public health and food supply. The fertility rate, however, remains high or even increases slightly. Stage 2 is characterised by increasingly rapid population growth. Subsequently, the proportion of children will be very high and as a result the proportion of consumers will be higher than that of producers. At this stage, the country needs to invest well in the children through quality education and training in order to prepare a highly qualified labour force that can give a boost to the economy in the future [11]. 
In stage 3 , substantial decline in fertility rates moves the population towards stability. This decline is mainly related to increased urbanization, better education and employment among women and availability of family planning programmes. As a result, the proportion of children starts to decline while the proportion of working age people starts to rise. Stage 3 has a particular period, called the "demographic window", which starts about 15 years after the decline in fertility and lasts for around $30-40$ years. The demographic window constitutes an economic bonus which can result in an economic boom if the country properly absorbs and productively employs the extra labour force [10].

Stage 4 is characterised by population stability and an increased proportion of elderly in the age structure, and thus increased dependency. In cases where the fertility rate declines below replacement level, the population may even start to decline. This period can again have a negative impact on economic growth if not tackled in policy $[10,11]$.

When a country fails to efficiently move through the demographic transition, the population constantly grows extremely rapidly due to high fertility and low mortality rates. Here the country ends up spending a big share of its resources to provide public services to the increasing population and will be stuck in what is called the "demographic trap" $[10,11]$.

\section{Experience of different regions}

Different regions of the world have different experiences in terms of accommodating population growth and applying policies to cope with the demographic transition.

East Asia entered the demographic transition very early and moved through it very rapidly. The decline in fertility rate was the effect of successful family planning programmes through encouraging contraception and providing incentives for decreasing birth rates. The governments were successful in tackling the baby boom through the provision of high quality education and training especially by expanding secondary education, which resulted in the production of a high quality labour force [10].

Furthermore, the policies of East Asia governments in encouraging investment and trading, investment in agriculture and industry as well as proper use of resources resulted in providing employment to the newly emerged labour force. These policies had enormous effects on reducing income inequalities. The increased job opportunities for women and decline in fertility rate have resulted in more women engaged in productivity, and thus further increased the proportion of producers. As a result, the region was very successful in exploiting the demographic bonus and experienced high economic growth rates, the so called "economic miracle". However, over the next $1-2$ decades, the dependency ratio may increase again in the region due to the effect of a growing proportion of elderly people, which may negatively affect the economic situation [12].

Latin America followed a similar population pattern as East Asia. The region experienced a dramatic fall in mortality rates followed by a decline in fertility rates. However, the region was not able to experience economic growth similar to that of eastern Asia. Actually, Latin America failed in properly exploiting the demographic bonus as a result of poor government policies, improper investment in building high quality labour forces, improper use of resources and lack of investment in trade [1].

In Sub-Saharan Africa the decrease in mortality rate was not followed by a decline in fertility rate. As a result the population continued to grow. In 1990 , around $45 \%$ of people in subSaharan Africa were living in extreme poverty. While this proportion only slightly increased by 2001 , this meant an additional 87 million people in poverty due to the effect of population growth. The rapid population growth in the region is an important obstacle to tackling poverty and apparently all efforts could not even keep the numbers of people living in extreme poverty stable [13].

While many countries in SubSaharan Africa are stuck in a demographic trap, there is no good evidence that countries that are moving through the demographic transition will be able to benefit from the demographic bonus. With the existing government policies and investments, it is quite unlikely that countries in Sub-Saharan Africa can follow the East Asia model. However, there is still time for these countries to adopt strategies to exploit such opportunities and promote economic growth [10].

\section{The case of Iraqi Kurdistan}

According to the 2007 population estimates and population projection, Iraqi Kurdistan is at the end of stage 2 of demographic transition and will enter stage 3 over the next few years. This can be concluded from the high total fertility rate of 4.07 and the current population age structure. According to the 2007 age structure, a very high percentage of people are in the age group 0-14 years $(39.45 \%)$, i.e. dependants. On the other hand, the workforce age group (15-64 years) has experienced little expansion $(57.57 \%)[7,8]$. According to population projections, Iraq, including the Kurdistan region, will continue to have a high proportion of dependants (36.3\%) in 2015 [7]. This association suggests that Iraqi Kurdistan is going to experience a long period in the demographic trap.

There are no systematic, efficient family planning programmes in Iraqi Kurdistan even though the fertility rate is very high. While there are some programmes existing, they are actually inefficient, and do not sustain wide coverage or effective provision of consultancy or distribution of contraceptive pills and condoms. The unmet need for 
contraception among Kurdish women is considerably high (29.3\%) leading to high unwanted fertility [14]. In fact, the government is still working with the systems and rules that were adopted in the 1980s to encourage fertility during the Iraq-Iran war, such as long maternity leave and incentives for children [15].

In terms of the related economic situation, the Iraqi economy is dominated by oil. In addition to having a high unemployment rate, ranging from $30 \%$ to $60 \%$, more than $66 \%$ of the labour force in Iraq work in service provision sectors rather than production sectors [16]. In the Kurdistan region, agriculture and tourism can contribute effectively to economic development. Kurdistan, in fact, has experienced an important advance in foreign and internal investment in many sectors during the last few years, but mainly in the oil sector [17].

Education is free in Iraq and there is extra support and a lot of incentives in Kurdistan towards encouraging education at all stages of study. Even though the education system is below international standards, the region has experienced some changes and advances in the system over the last few years. However, the country is facing serious challenges in terms of accommodating the growing generation in schools and universities. Furthermore, most of those who complete their studies end up working in public service sectors, i.e. they become dependent rather than productive.

With the current trend of high fertility rate and high population growth, Iraqi Kurdistan will most probably follow the African model. However, the level of poverty will not be as bad as in Sub-Saharan Africa owing to the oildominated economy. If the fertility rate constantly decreased and proper investment was made in education and training with good economic investment, Iraqi Kurdistan would follow the East Asia model of economic boom. Otherwise, it will follow the Latin America model of no significant economic growth.

\section{Discussion}

Many countries have managed to accommodate population growth to some extent and have been able to increase the average income in spite of population growth. Moderate population growth can be beneficial in particular situations. When economic growth is accompanied by moderate population growth, it can stimulate demand and encourage technological innovation and investment. Similarly, moderate labour force growth, combined with sufficient resources, good governance and investment policies and increased spending on education, can lead to economic development [4].

Meanwhile, it is also well documented that rapid population growth can slow development in developing countries, especially when they already suffer from the effects of poverty and food insecurity. Similarly, high fertility can reduce the amount of time and money spent on children's development at the family level. It is also true that poor people who have large families benefit less from public services like health and education when these cannot keep pace with population growth. Rapid population growth can also weaken government potential and exhaust its resources, making it much more difficult to invest in education and infrastructure to ensure economic development.

However, studying the implications of population growth on economic development without considering other factors such as fertility and mortality patterns, age structure of the population, and government policies would be neither informative nor useful [9]. Examination of the context of population changes and the effect of demography on development should take into consideration studying population alongside the effect of other determinants of economic development. The effect of population growth may vary widely, depending on the institutional, economic, cultural and demographic setting [2].
Determinants related to quality of population, age structure, political stability, government policies regarding family planning, investment in population and in economic means, as well as using the demographic transition opportunities are more important factors that influence economic development than merely population growth [18].

Promotion of family planning when the birth rate is high, as in Iraqi Kurdistan, is essential to pass through the demographic transition successfully. In addition to its direct role in reducing poverty, family planning will decrease maternal and childhood deaths, leading to women's empowerment and wellbeing, and contribute to the provision of better quality of services such as health and education. Provision of comprehensive, accessible and modern family planning services will eventually lead to more opportunities for women to work and thus contribute to increasing the proportion of producers and also support better rearing of children $[6,14]$. However, adoption of strict family planning policies in the current political context in Iraq is not easy and there are many challenges due to the association of ethnic, sectarian and territorial rights with population size.

The investment of the Kurdistan Regional Government in health and education of children and youth, especially during this critical period of baby boom and demographic transition, is crucial to obtain a high quality population with a specialized and strong labour force that will be an asset for economic development during the demographic window phase, especially since the region is already experiencing some trends of economic development.

Proper exploitation of the demographic bonus opportunity in the Kurdistan region will ensure effective economic development as such an opportunity occurs only once, and may not recur. Adoption of policies for strengthening the land, labour, industry, trade and markets as well as providing 
openings for trade, foreign investment and the creation of job opportunities at this demographic stage will enforce economic development [1].

\section{Conclusion}

Demographic transition is in a critical stage in Iraqi Kurdistan and there is a clear need for action in terms of adopting appropriate family planning policies in order to go through the transition smoothly.

As the demographic window will appear shortly after this transition is passed through, the Kurdistan government needs to strengthen the policies it has already initiated for better and more effective education, on-the-job training and health services, as well as proper investment and exploitation of important resources like oil, agriculture and tourism. However, the current political and demographic contexts of Kurdistan and Iraq as a whole hinder the adoption of large-scale, strict family planning policies.

\section{References}

1. Birdsall N, Kelley AC, Sinding S. Population matters: demographic change, economic growth, and poverty in the developing world. Oxford, Oxford University Press, 2003.

2. Sachs JD. Rapid population growth saps development. Science, 2002, 297:341.

3. Nathan K. Population and development within the ecosphere: one view of the literature. Population Index, 1991, 57(1):5-22.

4. The consequences of rapid population growth. Population change and development. Washington DC, World Development Report, World Bank, 1984, 3:39-65.

5. Preston SH, Donaldson P. Population growth and economic development: a discussion of eight major relationships that link demographic patterns and economic process. Asia-Pacific Population Journal, 1986, 1(2):3-12

6. Cleland J et al. Family planning: the unfinished agenda. Lancet, 2006, 368:1810-1827.

7. US Census Bureau. International data base: IDB table access for Iraq. 2008 [Online] (http://www.census.gov/ipc/www/idb/ country/izportal.html, accessed 5 November 2008).

8. Population statistics. Erbil, Ministry of Planning, Kurdistan Regional Government, 2008 [Online] (http://www.mop-krg. org/default.aspx?page=articles\&c=StatisticsbySubjects\&id=2 0 , accessed 15 November 2008).

9. O'Neill BC, MackKellar, FL, Lutz W. Population, economic development and environment. Population and climate change. Cambridge, Cambridge University Press, 2005:81-108.

10. Boserup E. The conditions of agricultural growth: the economics of agrarian change under population pressure. London, Allen \& Unwin, 1965. Cited in: Bloom ED, Canning D, Sevilla J. The demographic dividend, a new perspective on economic consequences of population change. Santa Monica, California, RAND
Corporation, RAND Population Matters Monograph Series, 2003:1-82.

11. Montgomery K. The demographic transition. Wausau, Wisconsin, University of Wisconsin Marathon County, Department of Geography and Geology [Online article] (http://www.uwmc. uwc.edu/geography/Demotrans/demtran.htm, accessed 30 May 2008).

12. Oshima $\mathrm{H}$. The industrial and demographic transition in East Asia. Population and Development Review, 1989, 9(4):583-605.

13. Return of the population growth factor, its impact upon the millennium development goals. London, Report of hearing by the All Party Parliamentary Group on Population, Development and Reproductive Health, 2007:20-30.

14. Agha SY, Rasheed BO. Family planning and unmet need among Iraqi Kurds. Eastern Mediterranean Health Journal, 2007, 13(6):1382-1391.

15. Iraq reproductive health assessment. United Nations Population Fund, 2003 [Online text] (http://www.unfpa.org/rh/docs/ iraq-rept04-08-03.doc, accessed 2 June 2008).

16. Iraq living conditions survey, 2004. Baghdad, Central Organization for Statistics and Information Technology, Ministry of Planning and Development Cooperation/United Nations Development Programme, 2005 [Online report] (http://www. fafo.no/ais/middeast/iraq/imira/Tabulation\%20reports/ english\%20atlas.pdf, accessed 18 August 2010).

17. Barkey HJ, Laipson E. Iraqi Kurds and Iraq's Future. Middle East Policy, 2005, 12(4):66-76.

18. Crensha EM, Ameen AZ, Christenson M. Population dynamics and economic development: Age-specific population growth rates and economic growth in developing countries 1965 to 1990. American Sociological Review, 1997, 62(6):974-984. 